\title{
Is Procalcitonin Useful in Early Diagnosis of Serious Bacterial Infections in Children?
}

\author{
Gupta $\mathbf{R}^{1}$, Singh $\mathbf{V}^{2}$, Patrikar $\mathbf{S}^{3}$, Hazra $\mathbf{N}^{4}$, Mathai \\ SS $^{5}$ \\ ${ }^{1}$ Dr. Rakesh Gupta, MBBS, MD, Professor \& Head, Dept \\ of Paediatrics, Command Hospital (CC) Lucknow, India, \\ ${ }^{2}$ Dr. Veena Singh, MBBS, MD, Assistant Professor, \\ ITBP Hospital, Chandigarh, India, ${ }^{3} \mathrm{Dr}$. Seema Patrikar, \\ MBBS, MD, Assistant Professor, Department of \\ Community Medicine, AFMC, Pune, India. ${ }^{4} \mathrm{Dr}$. Nandita \\ Hazra, MBBS, MD, Associate Professor, Department \\ of Microbiology, AFMC, Pune, India, ${ }^{5}$ Dr. SS Mathai, \\ MBBS, MD, Professor, INHS Ashwini, Mumbai, India.
}

\section{Introduction}

$\mathrm{D}$ iagnosis of bacterial infections remains one of the greatest and most tantalizing challenges in medical science, especially in children, in whom clinical signs are often nonspecific and confusing and hence laboratory parameters become crucial $^{1,2}$. The currently used markers for diagnosis of sepsis in children are not very specific. Marshall et al published a thorough report from the fifth Toronto sepsis round table on measures, markers and mediators of clinical sepsis and suggested that many circulating or cell-associated molecules have been found to be useful markers for the presence, severity, or response to therapy of sepsis ${ }^{3}$. In recent years, several newer markers of infection have been investigated, such as procalcitonin (PCT) and interleukins (IL-6 and IL-8), which are easy to perform and in combination have high sensitivity and specificity ${ }^{4-8}$. The aim of this study was to evaluate procalcitonin as early marker of serious bacterial infection in children.

\section{Materials and Methods}

This diagnostic evaluation study was carried out at a tertiary care hospital from Sep 2008 till Sep 2010, among newborns and children up to five years of age presenting with features suggestive of systemic inflammatory response syndrome (SIRS). All patients underwent standard tests / sepsis screen namely total leukocyte count (TLC), Differential leukocyte count (DLC),

\author{
Address for correspondence \\ Dr. Rakesh Gupta \\ Professor \& Head \\ Department of Paediatrics \\ Command Hospital (CC) Lucknow-226002 India \\ E-mail: colrgupta@gmail.com
}

\begin{abstract}
Introduction: Diagnosis of bacterial infections remains one of the greatest challenges in medical science, especially in children, in whom clinical signs are often nonspecific. The currently used sepsis screen has poor predictive value. Recently introduced marker procalcitonin (PCT) with high sensitivity and specificity is evaluated as early marker of serious bacterial infection in children. Materials and Methods: Children up to 5 years of age presenting with features of Systemic Inflammatory Response Syndrome(SIRS) were evaluated clinically and underwent standard sepsis screen namely total leukocyte count (TLC), peripheral blood smear for band count, C-reactive Protein (CRP) and newer tests like procalcitonin (PCT) and Interleukin-8 (IL-8). Results were analyzed using SPSS14.0. Results: One hundred patients suspected of sepsis were evaluated. Maximum cases were below one year (37\%) with mean age of 27 months. Male:female ratio was 1.5:1. Respiratory system was the commonest system involved in $(54 \%)$ followed by gastrointestinal $(20 \%)$, genitourinary $(10 \%)$ and central nervous system (5\%). Seventy two cases were found to have confirmed sepsis, proven by blood culture (34\%) and other investigations. Fifty two cases were diagnosed by conventional markers, while newer markers in 60 cases. Diagnostic evaluation revealed that newer markers have higher sensitivity and specificity as compared to conventional sepsis screen. Conclusion: Procalcitonin is a useful marker for diagnosis of serious bacterial infections in children and in combination with IL8 has a higher sensitivity and specificity as compared to standard sepsis screen. Therefore it is recommended that procalcitonin should be used for the screening of sepsis in children so that the treatment can be started earlier in order to prevent morbidity and mortality.
\end{abstract}

Key words: Systemic inflammatory response syndrome (SIRS), Sepsis screen, Procalcitonin, Interleukin-8

\section{How to cite this article?}

Gupta R, Singh V, Patrikar S, Hazra N, Mathai SS. Is Procalcitonin Useful in Early Diagnosis of Serious Bacterial Infections in Children? J Nepal Paediatr Soc 2013;33(2):106-109. 
peripheral blood smear for band count and C-reactive protein (CRP) by qualitative method using RHELAXCRP kit. They were also subjected to newer markers like procalcitonin (PCT) by semi-quantitative assay using bedside immunochromatography kit (B.R.A.H.M.S. PCT-Q, B.R.A.H.M.S.-Diagnostica GmbH, Hennigsdorf, Germany) and Interleukin-8 (IL-8) by human IL8/NAP-1 kit by ELISA method. Blood culture positivity was taken as gold standard for sepsis. Other cultures or corroborative investigations for proven sepsis were also considered as definite evidence of sepsis. The data was statistically analyzed using SPSS 14.0 to determine the sensitivity, specificity, positive and negative predictive values and likelihood ratios of the tests.

\section{Results}

Total 130 patients were considered for the study, of which 30 patients excluded as they did not fulfill the inclusion criteria. Maximum numbers of cases were in the age group of one month to one year $(37 \%)$ with mean age of 27 months and male:female ratio of 1.5 : 1. Maximum numbers of cases had involvement of respiratory system $(54 \%)$ followed by gastrointestinal $(20 \%)$, genitourinary $(10 \%)$ and central nervous system (5\%). Clinical profile of the study population is depicted in Figure 1 and 2.

Seventy two cases had evidence of proven sepsis by blood culture and other cultures (urine, CSF and other body fluids). Respiratory system was involved in the 41 cases $(57 \%)(95 \% \mathrm{Cl}, 44.3$ - 67.99), genitourinary in 12 (17\%) $(95 \% \mathrm{Cl}, 9.36$ - 26.6) and central nervous system in 10 cases $(14 \%)(95 \% \mathrm{Cl}, 7.28-23.36)$. Organisms were isolated from blood culture in 34 patients with commonest being staphylococcus aureus in 19 (55\%) children. Fifty two cases $(52 \%)(95 \% \mathrm{Cl}, 42-61)$ were diagnosed by the conventional markers namely total leukocyte count (TLC), band count and CRP, while 60 cases $(60 \%)(95 \% \mathrm{Cl}, 50.18$ - 69.25) were diagnosed by the newer markers like procalcitonin and IL-8 as shown in Table- 1.

Diagnostic evaluation of the conventional markers and newer markers was done and it was observed that CRP and band count have sensitivity of $69.7 \%$ (95\% Cl, 58-79.5) and 50.9\% (95\% Cl, 41-60.5), which was lower than newer markers like PCT and IL8 with the sensitivity of $84.8 \%(95 \% \mathrm{Cl}, 73-92)$ and $90.9 \%$ $(95 \% \mathrm{Cl}, 81-96)$ respectively. Similarly specificity of conventional markers CRP and band count was 54.8\% (95\% Cl, 45-63) and 44.4\% (95\% Cl, 34-55), which was also low as compared to the newer markers PCT and IL8 with specificity of $88.2 \%(95 \% \mathrm{Cl}, 72-96)$ and $82.4 \%$ (95\% Cl, 65-93). It was also observed that the PPV and NPV were high for the newer markers as compared to the conventional markers. On further analysis of newer markers PCT \& IL-8, when combined together had improved sensitivity of $90.3 \%(95 \%, \mathrm{Cl} 79.5-85)$ and specificity of $73.4 \%(95 \% \mathrm{Cl}, 51.8-85.1)$ as shown in Table 2.

Sensitivity of newer markers PCT and IL8 with respect to CRP was also evaluated and found $82.1 \%$ (95\% Cl and 70.4-90) and 83.6\% (95\% Cl, 72-91) and specificity $84.8 \%(95 \% \mathrm{Cl}, 67-94)$ and $90.9 \%(95 \% \mathrm{Cl}$, 75-95) respectively showing the superiority of newer markers over conventional markers. Similarly sensitivity of PCT and IL8 with respect to band count was $84 \%$ (95\% Cl, 73-92) and $91 \%(95 \% \mathrm{Cl}, 82-97)$ whereas the specificity $83 \%(95 \% \mathrm{Cl}, 67-93)$ and $87 \%(95 \% \mathrm{Cl}, 68-$ 95.6) showing the usefulness of newer markers over conventional markers as shown in Table 3.

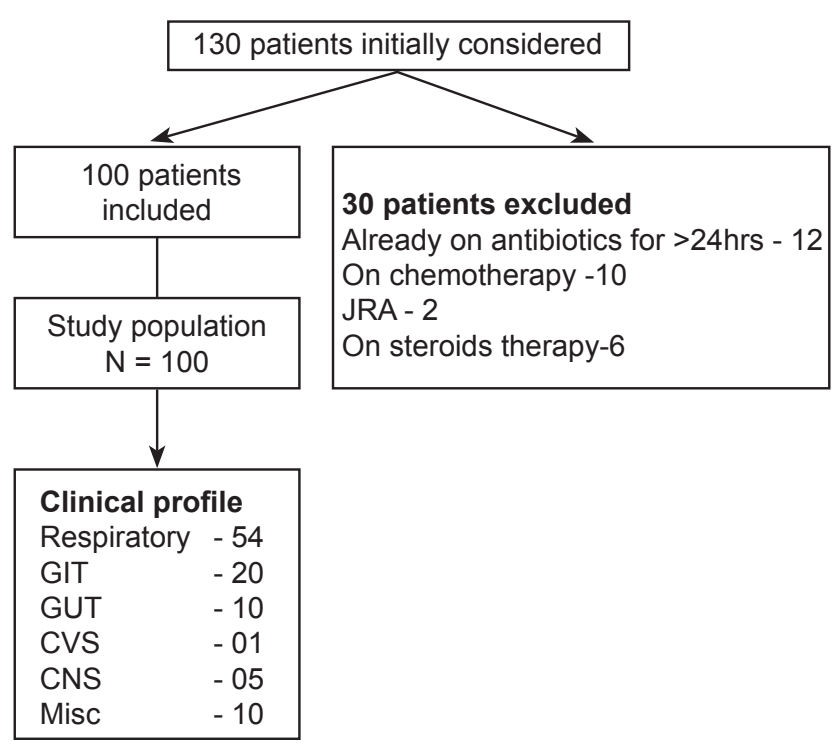

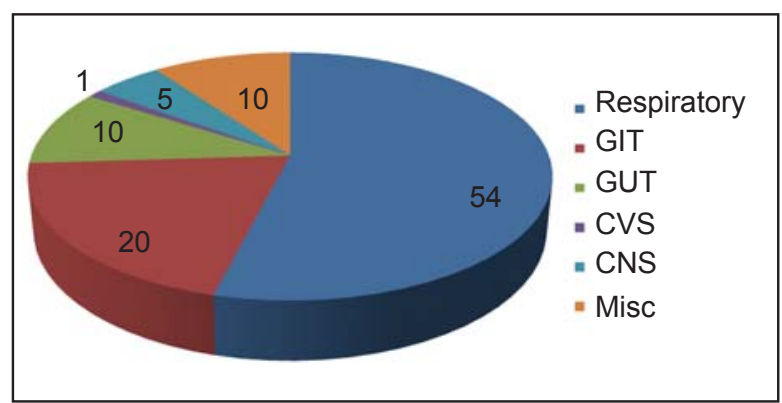

Fig 2: Showing the Clinical profile of sepsis in study population

Fig 1: Clinical profile of the study population 
Table 1: Sepsis in the study population

\begin{tabular}{|l|c|c|}
\hline \multicolumn{1}{|c|}{ Diagnosis of sepsis } & No. of cases & $\mathbf{9 5 \%} \mathbf{~ C l ~}$ \\
\hline $\begin{array}{l}\text { Confirmed sepsis (Gold standard and } \\
\text { other suggestive tests) }\end{array}$ & 72 & $62-81$ \\
\hline Diagnosed by conventional markers & 52 & $42-61$ \\
\hline Diagnosed by newer markers & 60 & $50-69$ \\
\hline \multicolumn{1}{|c|}{ Total number of cases } & $\mathbf{1 0 0}$ & \\
\hline
\end{tabular}

Table 2: Sensitivity and specificity of single and combination markers of infection

\begin{tabular}{|c|c|c|c|c|c|}
\hline Marker & Sensitivity (95\% CI) & Specificity (95\% CI) & PPV (95\% CI) & NPV (95\% CI) & LR value \\
\hline CRP & $69.7(58-79.5)$ & $54.8(45-63)$ & $48.6(39-58)$ & $74.7(64-98.3)$ & 1.56 \\
\hline Band forms & $50.9(41-60.5)$ & $44.4(34-55)$ & $52.8(43-62)$ & $42.6(32-53)$ & 1.05 \\
\hline PCT & $84.8(73-92)$ & $88.2(72-96)$ & $93.3(83-98)$ & $75(58-87)$ & 7.08 \\
\hline IL8 & $90.9(81-96)$ & $82.4(65-93)$ & $90.9(81-96)$ & $82.4(65-93)$ & 5.06 \\
\hline PCT + IL8 & $90.3(79.5-85)$ & $73.4(51.8-85.1)$ & $86.2(74-93)$ & $78.6(58.5-91)$ & 3.1 \\
\hline
\end{tabular}

Table 3: Comparison of sensitivity and specificity of markers of sepsis

\begin{tabular}{|c|c|c|c|c|c|c|}
\hline $\begin{array}{c}\text { Combination } \\
\text { markers }\end{array}$ & $\begin{array}{l}\text { Sensitivity } \\
(95 \% \mathrm{CI})\end{array}$ & $\begin{array}{l}\text { Specificity } \\
(95 \% \mathrm{CI})\end{array}$ & $\begin{array}{c}\text { PPV } \\
(95 \% \mathrm{Cl})\end{array}$ & $\begin{array}{c}\text { NPV } \\
(95 \% \mathrm{Cl})\end{array}$ & $\begin{array}{c}\text { Kappa coefficient } \\
\text { (P value) }\end{array}$ & LR ratio \\
\hline PCT Vs CRP & $82.1(70.4-90)$ & $84.8(67-94)$ & 91.7 (81-97) & $70(53-83)$ & $0.63(P=0.00)$ & 5.47 \\
\hline IL8 Vs CRP & 83.6 (72-91) & $90.9(75-98)$ & $95(85-98)$ & $73.2(57-85)$ & $0.70(P=0.00)$ & 9.33 \\
\hline РCT Vs BF & $84(73-92)$ & $83(67-93)$ & $90(79-96)$ & $75(56-87)$ & $0.66(P=0.00)$ & 4.94 \\
\hline IL8 Vs BF & $91(82-97)$ & $87(68-95.6)$ & $94.1(85-98)$ & $81(63-92)$ & $0.77(P=0.00)$ & 7 \\
\hline
\end{tabular}

\section{Discussion}

Early diagnosis of the severe infections and the prompt initiation of adequate antimicrobial therapy are essential for the good outcome in infants and young children ${ }^{1}$. Chiesa et al reported that an abnormal PCT concentration in early neonatal sepsis with a sensitivity of $92 \%$ and specificity of $97.5 \%{ }^{9}$. These findings were in agreement with our study, which showed the sensitivity and the specificity of PCT to be $85 \%$ and $88 \%$ respectively. Suprin E et al compared PCT and CRP in ICU patients and found that PCT had better specificity and sensitivity (93\% and 94\%) than CRP (75\% and $73 \%)^{10}$. Among the organisms isolated from the blood, staph aureus was the commonest isolated organism seen in $55 \%$ whereas in a study by Jose $\mathrm{R}$ gram negative organisms were found in maximum number of cases ${ }^{11}$.

Our study demonstrated that newer markers namely PCT and IL8 were more sensitive than CRP, TLC and band counts for predicting sepsis in children. Similarly specificity of these newer markers were higher that of CRP and band forms. Muller and colleagues investigated 101 patients admitted to medical ICU and found that PCT is a more reliable marker of sepsis than CRP, IL-6 and lactate levels ${ }^{12}$. A systematic review was published in 2004 investigating the value of PCT as a marker of bacterial infection in children and adults. Two of the 12 studies analyzed involved children, one of which had enrolled newborn infants, both demonstrated that PCT was more accurate marker than CRP for differentiating between viral and bacterial infections ${ }^{13,14}$. When combination markers PCT and IL8 were used by Carcello et al, sensitivity and specificity increased to $94 \%$ and $90 \%$. In our study the sensitivity increased to $90 \%$ and the specificity $73 \%{ }^{4}$. The future lies in demonstrating whether assaying PCT improves the prognosis of patients, by making early diagnosis possible and aiding with monitoring treatment.

\section{Conclusion}

Procalcitonin is a useful marker for in diagnosis of serious bacterial infections in neonates and children. Alone or in combination with IL8 it has a higher sensitivity and specificity as compared to standard markers like CRP. Therefore it is recommended that procalcitonin should be used for the screening of sepsis in neonates and children so that the treatment can be started earlier in order to prevent morbidity and mortality.

Acknowledgements: Nil

Funding: Armed Forces Medical Research committee fund

Conflict of interests: None stated

Permission from IRB: Yes 


\section{References}

1. Maria A E, Keith R P. Sepsis, Septic Shock, and Systemic Inflammatory Response Syndrome. In: Kliegman, Behrman, Jenson editors. $18^{\text {th }}$ ed. Nelson textbook of Pediatrics, Vol 1, 2008; 1094-99.

2. Khilnani P, Deopujari S, Carcillo J. Recent advances in sepsis and septic shock. Indian $J$ Pediatr 2008;75:821-29.

3. Marshall JC, Vincent JL; measures, markers and mediators: toward a staging system for clinical sepsis. A report of fifth Toronto sepsis Round table, Toronto, Ontario, Canada, October 25-26,2000. Crit Care Med 2003;31:1560-67.

4. Carcillo J A, Planquois J S, Goldstein B. Early markers of infection and sepsis in newborns and children. Adv Sepsis 2006;5(4):118-25.

5. Goldstein B, Giroir B, Randolph A. International Pediatric sepsis consensus conference: definition for sepsis and organ dysfunction. Pediatr Crit Care Med 2005;6:2-8.

6. Altunhan $\mathrm{H}$, Annagür $\mathrm{A}$, Ors $\mathrm{R}$, Mehmetoğlu I. Procalcitonin measurement at 24 hours of age may be helpful in the prompt diagnosis of early-onset neonatal sepsis. Int J Infect Dis 2011;15(12):e8548.

7. Uusitalo-Seppälä R, Koskinen P, LeinoA, Peuravuori $H$, Vahlberg T, Rintala EM. Early detection of severe sepsis in the emergency room: diagnostic value of plasma C-reactive protein, procalcitonin, and interleukin-6. Scand J Infect Dis 2011;43(1112):883-90.

8. Becker KL, Snider R, Nylen RS et al. Procalcitonin assay in systemic inflammation, infection, and sepsis: clinical utility and limitations. Crit Care Med 2008;36(3):941.

9. Chiesa C, Panero A, Rossi et al. Reliability of PCT concentrations for sepsis in critically neonates. Clin Infect Dis 1998;26:664-72.

10. Suprin E, Camus C, Gacouin A, et al.procalcitonin and infection in a medical ICU? Intensive Care Med 2000;1232-38.

11. Jose R F, Fernanda C B, Rossano C B et al. Procalcitonin in children with sepsis and septic shock. J Pediatr 2007;89:876-82.

12. Muller B, Becker K L,Schachinger $\mathrm{H}$ et al. Reliable markers of sepsis in a medical care unit. Crit Care Med 2000;28: 977-98.

13. Simon L, Gauvin F, Amre DK, Saint-Louis P, Lacroix J. Serum procalcitonin and C-reactive protein levels as markers of bacterial infection: a systematic review and meta-analysis. Clin Infect Dis 2004;39:206-17.

14. Hatherill M, Tabby SM, Turner C, et al: Diagnostic markers of infection: Comparison of PCT and CRP and leukocyte count. Arch Dis Child 1999;81:20617. 